\title{
К ВОПРОСУ ОБ ЭПИДЕМИОЛОГИИ И ЛЕЧЕНИИ ОСТРЫХ И ХРОНИЧЕСКИХ РАН
}

\section{EPIDEMIOLOGY AND TREATMENT OF ACUTE AND CHRONIC WOUNDS}

\author{
V. Vasin \\ V. Stupin \\ K. Koreyba \\ V. Yagzhina \\ E. Senina \\ V. Seluto \\ E. Silina
}

Summary. The review of the world literature discusses the frequency of occurrence of acute and chronic wounds of various origins in different countries, as well as the financial costs of their treatment. The results of meta-analyzes and systematic reviews on the effectiveness of various agents and methods used to treat wounds are presented. The authors come to the conclusion that the problem is of great urgency, but there are no uniform and effective approaches and medicines for the treatment of wounds. In this regard, an extremely urgent and promising is the development of improved means for the treatment of wounds based on the pathogenetic mechanisms of regeneration.

Keywords: wound, skin wounds, acute wound, chronic wound, wound prevalence, epidemiology, wound treatment, review, meta-analysis.
Васин Виталий Иванович

Ассистент, соискатель, ФГБАУ ВО РНИМУ

им. Н.И. Пирогова Минздрава России (г. Москва)

Ступин Виктор Александрович

Д.м.н., профессор, ФГБАУ ВО РНИМУ им. Н.И. Пирогова

Минздрава России (2. Москва)

Корейба Константин Александрович

К.м.н., дочент, ФГБОУ ВО Казанский государственный медицинский университет

Минздрава России (г. Казань)

Ягжина Вероника Евгеньевна

ФГАОУ ВО Первый МГМУ им. И.М. Сеченова Минздрава России (Сеченовский университет)

(2. Москва)

Сенина Елена Руслановна

ФГАОУ ВО Первый МГМУ Им. И.М. Сеченова Минздрава России (Сеченовский университет)

(2. Москва)

Селюто Вероника Васильевна

ФГАОУ ВО Первый МГМУ им. И.М. Сеченова

Минздрава России (Сеченовский университет)

(г. Москва)

Силина Екатерина Владимировна

Д.м.н., професссор, ФГАОУ ВО Первый МГМУ им. И.М. Сеченова Минздрава России (Сеченовский университет) (2. Москва) silinaekaterina@mail.ru

Аннотация. В представленном обзоре мировой литературы обсуждается частота встречаемости острых и хронических ран различного генеза в разных странах, а также финансовые расходы на их лечение. Представлены результаты метаанализов и систематических обзоров по эффективности разных средств и методов, используемых для лечения ран. На основании выполненного обзора авторы приходят к выводу 0 том, что, несмотря на высокую актуальность проблемы, до настоящего момента нет единых и эффективных подходов и лекарственных средств для лечения ран. В данной связи чрезвычайно актуальным и перспективным является разработка совершенных средств для лечения ран, основанных на патогенетически обоснованных механизмах регенерации.

Ключевые слова: рана, кожные раны, острая рана, хроническая рана, распространенность ран, эпидемиология, лечение ран, метаанализ, обзор. 
Л ечение кожных ран - это комплексная междисциплинарная проблема, требующая адекватного состояния множества физиологических и иммунологических процессов, а также физических, а в случае хронизации и социальных факторов, содружественно отвечающих за успех закрытия раневого дефекта. Изучение клеточных и молекулярных механизмов, лежащих в основе заживления ран, позволяющих эффективно ускорять процесс регенерации, занимает исследователей и клиницистов много лет, и интерес этот не ослабевает, так как раны являются самым частым состоянием, с которым обращаются к специалистам хирургического профиля.

В клинической практике кожные раны принято делить на острые и хронические [1, 2]. Острая рана - это внезапное повреждение кожи, включая хирургические вмешательства. Хронические раны длительно не заживают (без признаков эпителизации более 6 недель) и могут быть опасны для жизни вследствие присоединения кровотечения, остеомиелита и сепсиса, но всегда десоциализируют пациента (пролежни, хронические венозные язвы, синдром диабетической стопы). Количество острых ран в мире непрерывно увеличивается, что связано с ростом бытовых и военных травм, когда острая рана возникает у соматически здорового человека, а также с ростом числа операций в мире [3-8]. В частности, по данным НИИ организации здравоохранения и медицинского менеджмента Департамента Здравоохранения г. Москвы количество операций в столице увеличилось с 611940 в 2010 году до 837114 в 2018, причем операции на коже и мягких тканях возросли почти в 2 раза, с 64481 до 119380. Число людей, страдающих от хронических ран, также непрерывно увеличивается, что связано не только с ростом продолжительности жизни, а значит и увеличением коморбидных патологий $[2,9-13]$. Некоторые исследователи утверждают, что в мире насчитывается около 100 млн. человек, страдающих от острых травматических ран и 300 млн. человек с хроническими ранами [14]. Однако точных эпидемиологических данных по ранам в настоящее время нет, а имеющиеся опубликованные работы по этой теме носят раздробленный характер, касаются лишь отдельной ее проблеме, но свидетельствуют о том, что общее количество ран гораздо больше. Таким образом, вопросы заживления кожных ран различной этиологии и их эффективное лечение, несмотря на богатый арсенал имеющихся и постоянно появляющиеся и внедряющихся в практическое здравоохранение новых средств и методов, используемых для лечения ран, продолжают оставаться в числе высоко актуальных.

Хотя эпидемиологические исследования, посвященные оценке числа хронических ран их эффективности и лечения, в мире немногочисленны, а опубликован- ные исследования показывают большие различия, попытаемся разобраться и в этом вопросе. По данным систематического обзора и метаанализа обсервационных исследований, проведенных в период 2000-2018 гг. общая распространенность среди взрослых хронических ран смешанной этиологии (всего 3 исследования) составила 2,21 на 1000 населения, а для хронических язв на нижних конечностях (9 исследований) $-1,51$ на 1000 взрослого населения [15]. По данным эпидемиологического исследования пациентов с хроническими ранами, проведенного в Германии по анализу данных обязательного медицинского страхования с участием 9 миллионов застрахованных лиц в течении 3 лет (с 2010 по 2012 гг.), лечение ран было проведено у 0,43\% пациентов, причем распространенность и заболеваемость хронических ран увеличились за 3 года в 1,3 раза; общая распространенность ран составила 786407 и 196602 случаев лечения хронических ран [16]. Исследование, проведенное в одном из городов Великобритании (население 751485 человек, обследовано 1103 человека) показало, что распространенность хронических ран составила 1,47 на 1000 населения, выше она была среди женщин, чем у мужчин (1,63 и 1,28 на 1000, соответственно) и существенно увеличивалась с возрастом, достигая максимума у людей в возрасте 90 лет и старше (22,88 на 1000); самыми частыми были трофические язвы на ногах и пролежни $(0,44$ и 0,31 на 1000 населения, соответственно) [17].

Среди хронических длительно незаживающих ран сосудистого происхождения наиболее распространёнными являются венозные трофические язвы, на их долю выпадает 50-70\% [15, 18-22]. Хронические раны, развившиеся вследствие артериальной недостаточности, составляют, по данным ряда авторов, 5-25\% от общего числа длительно незаживающих язв, а на долю смешанных артериально-венозных язв выпадает 10-20\% [15, 19, 22-23]. Остальные трофические раны обусловлены множеством других патологий. Особую проблему составляют прогрессивно увеличивающиеся длительно незаживающие раны при сахарном диабете (синдром диабетической стопы), которые не входили в статистику вышеприведенных исследований. По данным систематического обзора глобальная мировая распространенность синдрома диабетической стопы составляет 6,3\%, колеблясь по разным оценкам в пределах 4-8\%, то есть СДС страдают не менее 50 млн. жителей планеты [11, 24-25].

Лечение ран у этих пациентов является мероприятием дорогостоящим. Единых точных данных о затратах в мире нет. Имеется лишь анализ по отдельным видам ран в отдельных популяциях. Так, на лечение хронических ран в США ежегодно тратятся около 20 миллиардов долларов, а в Великобритании - около 184 миллионов 
фунтов стерлингов [26, 27]. Имеются и другие данные о том, что на лечение только венозных ран нижних конечностей в небольшом по населению городе Англии (г. Лидс) тратится от 300 до 600 миллионов фунтов стерлингов в год [17]. Десять лет назад американские страховщики опубликовали финансовую сторону ведения больных с синдромом диабетической стопы сообщив о том, что на уход за диабетической стопой ежегодно тратится не менее 18 млрд. долларов США, а 11,7 млрд. долларов расходуются на ампутации нижних конечностей в связи с безуспешностью лечения [28].

Таким образом, в связи с ростом проблемы кожных ран, лечение которых несет существенные экономические затраты, актуализируется необходимость в разработке доступных эффективных средств и методов лечения ран, способствующих максимально эффективно использовать биологические механизмы, заложенные в регенерации тканей кожи. Очевидно, что актуальным и перспективным является фундаментальное изучение процессов регенерации и механизмов действия стимулирующих заживление ран лекарственных средств, что совместно с развитием персонализированной медицины будет способствовать наиболее эффективному и безопасному лечению.

За последние десятилетия было создано множество продуктов для лечения ран, влияющих на различные механизмы и процессы заживления, которые могут быть нарушены вследствие разных местных и системных факторов. Поскольку пока не разработано универсального регенерирующего средства, целесообразным остается персонализированный подход к выбору средства и метода лечения ран в соответствии с факторами, препятствующими или способствующими их заживлению $[29,30]$.

Самым распространенным является применение перевязочного материала для лечения ран, который изготавливают в различных формах, таких как гидрогели, пленки, нановолокна, пены, составы для местного применения, пластыри, повязки. Среди них общеприняты для использования сегодня являются гидрогелевые повязки. Zhang L. et al. (2019) провели систематический обзор и метаанализ с оценкой клинической эффективности и безопасности медицинских гидрогелевых повязок, используемых при лечении кожных ран на основе данных PubMed / Medline (1980-2019), Кокрановской библиотеки (1980-2019) и других научных баз, включающих публикации по этому вопросу за последние 40 лет [31]. Авторами было найдено 43 исследования, анализ которых установил эффективность гидрогелевых повязок (по сравнению с негидрогелевыми), что выражалось в ускорении заживления ожоговых ран II степени (поверхностных и глубоких), язв диабе- тической стопы, травматических повреждений кожи, радиоактивных повреждений кожи, укусов собак и язв на поверхности тела, а также показано положительное их влияние на купирование болевого синдрома. В то же время не было получено значительных различий между гидрогелевыми и негидрогелевыми повязками по времени и характеру заживления хирургических ран, пролежней и венозных трофических язв [31].

Успехи хирургического лечения ран ограничены, как правило, множеством соматических факторов. В систематическом обзоре и метаанализе 11 исследований хирургического лечения ран в сравнении с консервативной терапией сделан вывод о том, что хирургическое вмешательство может улучшить заживление венозных язв, однако качество имеющихся доказательств является недостаточным по причине низкого уровня выполненных исследований [32].

Кохрейновский обзор, выполненный Norman G. et al. (2016) с целью оценить эффективность системных и местных антибиотиков, а также местных антисептиков при лечении хирургических ран вторичным натяжением (включено 11 исследований, в которых приняли участие 886 человек), показал отсутствие убедительных доказательств относительной эффективности каких-либо антисептических, антибиотических и/или антибактериальных препаратов, используемых для заживления хирургических ран вторичным натяжением [33]. Доказательства возможных эффектов классифицированы как доказательства среднего или низкого качества, так как основывались они на отдельных исследованиях с небольшим числом участников, что означает необходимость проведения дальнейших исследований [33].

Эти же авторы, Norman G. et al. (2018), провели метаанализ и систематический обзор 78 рандомизированных клинических исследований (7014 участников) для оценки эффективности повязок и местных средств, применяемых для заживления венозных язв нижних конечностей на разных этапах оказания медицинской помощи. В итоге авторы пришли к заключению о необходимости дальнейших исследований в связи низкой достоверностью выполненных в работах сравнений. Ранжировать методы лечения в порядке их эффективности и качества доказательств авторам не удалось [34].

Webster J. et al. (2019) провели систематический обзор 25 исследований (2957 участников) для оценки влияния терапии ран отрицательным давлением на предотвращение инфицирования области хирургического вмешательства при заживлении ран путем первичного закрытия. Авторы тоже получили доказательства низкой достоверности и сделали вывод об отсутствии значимого влияния терапии ран отрицательным дав- 
лением по сравнению со стандартным лечением ран на частоту таких важных исходов, как смертность, расхождение краев ран, серома, при этом стоимость такого лечения существенно увеличивалась [35].

Westby M.J. et al. (2017) провели метаанализ 39 исследований, оценивающих 21 тип лекарственных повязок и местные средства для лечения пролежней, и пришли к заключению о немногочисленности таких исследований, проводимых на должном уровне, а имеющиеся доказательства имеют низкую или очень низкую достоверность, что преимущественно связано с высоким риском систематической ошибки [36].

Таким образом, несмотря на широкий арсенал средств и методов, используемых для лечения ран, проблема их заживления до сих не решена. Многие из используемых в настоящее время консервативных средств и перевязочных материалов имеют ряд ограничений, таких как недостаточное противомикробное действие, слабые механические характеристики, плохой газообмен между раной и окружающей средой, трудности при удалении, индукция аллергических реакций, низкая абсорбция раневого экссудата и их неспособность поддерживать влажную среду для ускоренного заживления ран и многое другое. В данной связи чрезвычайно перспективным является разработка совершенных и экономичных средств для лечения ран, основанных на патогенетически обоснованных механизмах регенерации. Этим вопросам посвящены наши последние исследования [37-40].

\section{ЛИТЕРАТУРА}

1. Sorg H, Tilkorn DJ, Hager S, Hauser J, Mirastschijski U. Skin Wound Healing: An Update on the Current Knowledge and Concepts. Eur Surg Res. 2017;58(1-2):8194. https://doi.org/10.1159/000454919.

2. Stupin V.A, Gabitov R.B., Sinelnikova T.G, Silina EV. Biological mechanisms of the chronic wound and diabetic foot healing. Serbian Journal of Experimental and Clinical Research. 2018;19(4):373-382. https://doi.org/10.2478/SJECR-2018-0077

3. Гареев И.Ф., Бейлерли 0.А.О. Сочетанная кранио-абдоминальная травма. Клиническая эпидемиология. Российский нейрохирургический журнал им. профессора А.Л. Поленова. 2018; 10(5):25-26.

4. Пьянкова А.И., Фаттахов Т.А. Потерянные годы здоровой жизни в результате дорожно-транспортных происшествий в России. Профилактическая медицина. 2017;20(5):30-36. https://doi.org/10.17116/profmed201720530-36

5. Aghdash S, Aghaei MH, Sadeghi-Bazarghani H. Epidemiology of Road Traffic Injuries among Elderly People; A Systematic Review and Meta-Analysis. Bull Emerg Trauma. 2018;6(4):279-291. doi: 10.29252/beat-060403.

6. Rosberg HE, Dahlin LB. An increasing number of hand injuries in an elderly population — a retrospective study over a 30-year period. BMC Geriatr. 2018;18(1):68. https://doi.org/10.1186/s12877-018-0758-7

7. Cai Y-L, Ju J-T, Liu W-B, Zhang J. Military trauma and surgical procedures in conflict area: a review for the utilization of forward surgical team. Mil Med. 2018;183: e97-e106. https://doi.org/10.1093/milmed/usx048

8. Wild H, Stewart BT, LeBoa C, Stave CD, Wren SM. Epidemiology of Injuries Sustained by Civilians and Local Combatants in Contemporary Armed Conflict: An Appeal for a Shared Trauma Registry Among Humanitarian Actors. World J Surg. 2020;44(6):1863-1873. doi: 10.1007/s00268-020-05428-y.

9. Дибиров М.Д., Магдиев А.Х. Лечение венозных трофических язв в старческом возрасте. Флебология. 2016;10(4):224-228. https://doi.org/10.17116/ flebo2016104224-228

10. Румянцева С.А., Ступин В.А., Оганов Р.Г., Силина Е.В. [и др.] Теория и практика лечения больных с сосудистой коморбидностью: клиническое руководство. Миттель Пресс. - Москва, 2016. - 376 с.

11. Ступин В.А., Силина Е.В., Корейба К.А., Горюнов С.В. Синдром диабетической стопы (эпидемиология, патофизиология диагностика и лечение). М.: ЛитTeppa, 2019. - 192 c.

12. Antonopoulos CN, Lazaris A, Venermo M, Geroulakos G. Predictors of Wound Healing Following Revascularization for Chronic Limb-Threatening Ischemia. Vasc Endovascular Surg. 2019; Aug12:1538574419868863. https://doi.org/10.1177/1538574419868863

13. Han G, Ceilley R. Chronic Wound Healing: A Review of Current Management and Treatments. Adv Ther. 2017;34(3):599-610. https://doi.org/10.1007/s12325017-0478-y

14. Das S, Baker AB. Biomaterials and Nanotherapeutics for Enhancing Skin Wound Healing. Front Bioeng Biotechnol. 2016;4:82. https://doi.org/10.3389/ fbioe.2016.00082

15. Martinengo L, Olsson M, Bajpai R, Soljak M, Upton Z, Schmidtchen A, Car J, Järbrink K. Prevalence of chronic wounds in the general population: systematic review and meta-analysis of observational studies. Ann Epidemiol. 2019;29:8-15. doi: 10.1016/j.annepidem.2018.10.005.

16. Heyer K, Herberger K, Protz K, Glaeske G, Augustin M. Epidemiology of chronic wounds in Germany: Analysis of statutory health insurance data. Wound Repair Regen. 2016;24(2):434-42. doi: 10.1111/wrr.12387.

17. Hall J, Buckley HL, Lamb KA, Stubbs N, Saramago P, Dumville JC, Cullum NA. Point prevalence of complex wounds in a defined United Kingdom population. Wound Repair Regen. 2014;22(6):694-700. doi: 10.1111/wrr.12230.

18. Туркин П.Ю., Родионов С.В., Сомов Н.0., Миргатия И.0. Венозные трофические язвы: современное состояние вопроса. Лечебное дело. $2018 ; 1: 41-45$. 
19. Толстых П.И., Тамразова О.Б., Гейниц А.В., Раджабов А.А., Молочков А.В. Классификация длительно не заживающих и хронических ран (язв) нижних конечностей. Лазерная медицина. 2012; 16(3):3-14.

20. Abbade LP, Lastória S. Venous ulcer: epidemiology, physiopathology, diagnosis and treatment. Int J Dermatol. 2005;44(6):449-56.

21. van Gent W.B., Wilschut E.D., Wittens C. Management of venous ulcer disease. BMJ. 2010; 341: c6045. doi: 10.1136/bmj.c6045.

22. Olsson M, Järbrink K, Divakar U, Bajpai R, Upton Z, Schmidtchen A, Car J. The humanistic and economic burden of chronic wounds: A systematic review. Wound Repair Regen. 2019;27(1):114-125. doi: 10.1111/wrr.12683.

23. Hafner J, Buset C, Anzengruber F, Barysch-Bonderer M et al. Leg ulcers (ulcus cruris): The frequent macrovascular causes. Ther Umsch. 2018;75(8):506-514.

24. Zhang P, Lu J, Jing Y, Tang S, Zhu D, Bi Y. Global epidmiology of diabetic foot ulceration: a systematic review and meta-analysis. Ann Med. 2017;49(2):106-116.

25. Peter-Riesch B. The Diabetic Foot: The Never-Ending Challenge. Endocr Dev. 2016;31:108-34.

26. Frykberg RG, Banks J. Challenges in the Treatment of Chronic Wounds. Adv Wound Care. 2015; 4: 560-82.

27. Schmidtchen A., Pang C., Ni G., Sönnergren H., Car J., Järbrink K., Bajpai R. The humanistic and economic burden of chronic wounds: A protocol for a systematic review. Syst. Rev. 2017;6:7.

28. Rogers LC, Lavery LA, Armstrong DG. The right to bear legs. J Am Podiatr Med Assoc. 2008; 98: 166-168.

29. Dhivya S., Padma V.V., Santhini E. Wound dressings — A review. BioMedicine. 2015;5:24-28. doi: 10.7603/s40681-015-0022-9.

30. Haalboom M. Chronic wounds: innovations in diagnostics and therapeutics. Curr Med Chem. 2018;25(41):5772-5781. doi:10.2174/09298673246661707101 20556

31. Zhang L, Yin H, Lei X, et al. A Systematic Review and Meta-Analysis of Clinical Effectiveness and Safety of Hydrogel Dressings in the Management of Skin Wounds. Front Bioeng Biotechnol. 2019;7:342. doi:10.3389/fbioe.2019.00342

32. Mauck KF, Asi N, Undavalli C, et al. Systematic review and meta-analysis of surgical interventions versus conservative therapy for venous ulcers. J Vasc Surg. 2014;60(2 suppl):60S-70S.

33. Norman G, Dumville JC, Mohapatra DP, Owens GL, Crosbie EJ. Antibiotics and antiseptics for surgical wounds healing by secondary intention. Cochrane Database Syst Rev. 2016;3(3): CD011712. doi: 10.1002/14651858.CD011712.pub2.

34. Norman G, Westby MJ, Rithalia AD, Stubbs N, Soares MO, Dumville JC. Dressings and topical agents for treating venous leg ulcers. Cochrane Database Syst Rev. 2018 Jun 15;6(6): CD012583. doi: 10.1002/14651858.CD012583.pub2.

35. Webster J, Liu Z, Norman G, Dumville JC, Chiverton L, Scuffham P, Stankiewicz M, Chaboyer WP. Negative pressure wound therapy for surgical wounds healing by primary closure. Cochrane Database Syst Rev. 2019 Mar 26;3(3): CD009261. doi: 10.1002/14651858.CD009261.pub4.

36. Westby MJ, Dumville JC, Soares M0, Stubbs N, Norman G. Dressings and topical agents for treating pressure ulcers. Cochrane Database Syst Rev. 2017 Jun 22;6(6): CD011947. doi: 10.1002/14651858.CD011947.pub2.

37. Silina EV, Khokhlov NV, Stupin VA, Manturova NE, et al. Multicomponent polysaccharide essential formula of wound healing medicines enriched with fibroblast growth factor. International Journal of Biomedicine. 2019; 9(3):247-250. https://doi.org/10.21103/Article9(3)_0A12

38. Silina E, Manturova N, Stupin V. Mesenchymal Stem Cells Application in Wound Tissue Healing in Old Animals. Stem Cells and Cloning: Advances and Applications. 2020;13:103-116. https://doi.org/10.2147/SCCAA.S267967

39. Stupin V, Manturova N, Silina E, Litvitskiy P, Vasin V, et al. The Effect of Inflammation on the Healing Process of Acute Skin Wounds Under the Treatment of Wounds with Injections in Rats. J Exp Pharmacol. 2020;12:409-422. https://doi.org/10.2147/JEP.S275791

40. Silina EV, Manturova NE, Vasin VI et al. Efficacy of A Novel Smart Polymeric Nanodrug in the Treatment of Experimental Wounds in Rats. Polymers. 2020;12: e1126. https://doi.org/10.3390/polym12051126

\footnotetext{
(с) Васин Виталий Иванович, Ступин Виктор Александрович, Корейба Константин Александрович,

Ягжина Вероника Евгеньевна, Сенина Елена Руслановна,

Селюто Вероника Васильевна, Силина Екатерина Владимировна ( silinaekaterina@mail.ru ).

Журнал «Современная наука: актуальные проблемы теории и практики»
} 